\title{
ОБЩЕСОЦИАЛЬНЫЕ ДЕТЕРМИНАНТЫ РЕЦИДИВНОЙ ПРЕСТУПНОСТИ
}

\begin{abstract}
Современная российская преступность характеризуется высокими показателями рецидива. Каждое второе расследованное преступление совершается лицами, ранее совершавшими преступления. Указанное обусловливает необходимость выявления детерминант рецидивной преступности. Раскрыты общесоциальные детерминанты рецидивной преступности, т.е. явления и процессы, действующие на уровне общества в целом, выражающиеся в противоречиях экономической, политической, социальной и духовной сфер жизни общества.

Ключевые слова: рецидив; преступность; общесоциальные детерминанты; причины преступности; криминогенные факторы.
\end{abstract}

Современная российская преступность характеризуется высоким уровнем рецидивной преступности. По данным статистики, каждое второе расследованное преступление $(58,3 \%$ в 2018 г.) совершается лицами, ранее совершавшими преступления, т.е. теми, кто за предыдущее преступление уже привлекался к уголовной ответственности [1]. Совершение преступления после того, как к лицу были применены меры уголовно-правового воздействия, свидетельствует о несовершенстве таких мер, показывает их несостоятельность в деле предупреждения новых преступлений и обусловливает необходимость изучения причин и условий рецидива. Установление и классификация множества взаимосвязанных детерминант будут способствовать совершенствованию превентивной деятельности в сфере противодействия рецидивной преступности.

В литературе в качестве детерминант рецидивной преступности рассматриваются различные социальные явления и процессы, совместное действие которых порождает рецидив. При изучении причин данного феномена авторы используют разнообразные подходы. Так, Н.С. Артемьев, Р.В. Симонов выделяют объективные и субъективные факторы рецидивной преступности. К объективным они относят разнообразный круг обстоятельств организационного, правового, воспитательного характера, социальную среду, содержащую обстоятельства, приведшие лицо к совершению первого преступления, а также обстоятельства, созданные преступной деятельностью рецидивиста или ранее назначенным ему наказанием. Субъективными детерминантами, по их мнению, выступают характеристики личности рецидивиста, так как преступник становится рецидивистом в силу антиобщественной направленности личности [2. С. 6].

Другие авторы, подразделяя причины и условия рецидивной преступности на первичные и вторичные, первичными называют те, которые обусловили совершение первого преступления, вторичными - факторы, которые повлияли на рецидивную преступность. К последним данные исследователи относят обстоятельства, обусловившие неблагоприятное протекание постпенитенциарной адаптации, и условия, связанные с различными недостатками в деятельности правоохранительных органов и судов [3. С. 740].

Еще одна группа авторов, отмечая, что рецидивная преступность является частью преступности в целом и испытывает на себе влияние общего причинного комплекса преступности, выделяют общие (для всей преступности) и специальные (для рецидивной) причины и условия. «На рецидивную преступность воздействуют в разной мере две группы обстоятельств: общие для всей преступности причины и условия и специфические обстоятельства, складывающиеся как после совершения преступления, так и после отбытия наказания или заменяющей его меры» [4. С. 190-191].

На наш взгляд, при изучении детерминант рецидивной преступности целесообразно использовать уровневый подход, при котором причины и условия преступности исследуются на трех уровнях: общесоциальном, социально-психологическом и индивидуальном. По обоснованному мнению криминологов, данный подход к воспроизводству преступности является ключевым в российской криминологии, так как позволяет увязать конкретные социальные феномены (одним из которых выступает рецидив преступлений) с общесоциальной проблематикой [5. С. 88].

Общесоциальные детерминанты преступности это явления и процессы, действующие на уровне всего общества в целом; они выражаются в противоречиях социального бытия и общественного сознания и проявляются в различных сферах жизнедеятельности. На социально-психологическом уровне причины преступности действуют в рамках малых социальных групп, в которых происходило формирование личности преступника. В основе причин рецидивной преступности на данном уровне лежат особенности микросреды рецидивистов, которые оказывают непосредственное влияние на его личность и мотивацию поведения, а также недостатки деятельности различных субъектов предупреждения преступности. На индивидуальном уровне в качестве причин и условий рецидива выступают антиобщественные свойства лица, совершающего преступление после осуждения за предыдущее, и криминогенная ситуация, которые во взаимодействии обусловливают возвращение лица к преступной деятельности.

Существование и воспроизводство рецидивной преступности обусловлены негативными явлениями и процессами, происходящими в обществе. Криминологические исследования указывают на необходимость учета особенностей развития явлений и процессов в таких сферах общественной жизни, как экономика, политика, социальная и духовная сферы. Исследова- 
ние общесоциальных детерминант рецидивной преступности предполагает изучение состояния экономических, политических и других отношений и их влияния на состояние рецидивной преступности.

Общеизвестно, что среди детерминант преступности определяющая роль принадлежит тем, которые действуют в экономической сфере, поскольку экономика в главном и основном обусловливает социальные, политические и духовные процессы в обществе [6. С. 150]. В последние годы экономика нашей страны сталкивается с рядом проблем, которые в самом общем виде проявляются в неустойчивости экономического развития, в снижении темпов производства и абсолютном сокращении объемов производства как отдельных предприятий, так и целых отраслей национальной экономики. Безработица и инфляция оказывают негативное влияние на состояние производства и сдерживают экономический рост. Снижение результатов производства в реальном секторе экономики сказывается на доходах бюджетов всех уровней, приводят к банкротству не только мелких, средних, но и крупных предприятий [7. С. 130].

В условиях рыночных отношений, жесткой конкуренции на рынке труда, хозяйствующие субъекты не заинтересованы в использовании труда осужденных. Администрации муниципальных образований обладают весьма ограниченным перечнем объектов для отбывания наказания в виде обязательных и исправительных работ. Предприятия, особенно в сельских районах, не располагают необходимым количеством рабочих мест, не желают принимать на работу осужденных, у которых зачастую отсутствует образование и квалификация соответствующего профиля. Поэтому значительное число осужденных к обязательным и исправительным работам, а также условно осужденных не работают в период нахождения на учете в уголовно-исполнительной инспекции.

Высокий уровень безработных сохраняется среди осужденных, отбывающих наказания в местах лишения свободы - около трети (264 тыс.) [8]. Так, промышленный сектор уголовно-исполнительной системы испытывает трудности в виду отсутствия необходимых объемов работ, значительного износа оборудования, с одной стороны, и отсутствия у осужденных трудовых навыков и экономического стимула к труду - с другой.

Как подчеркивается в Федеральной целевой программе «Развитие уголовно-исполнительной системы (2018-2026 гг.)», высокий уровень неработающих осужденных создает серьезные проблемы для органов исполнительной власти субъектов Российской Федерации при решении задач по трудоустройству лиц, освободившихся после отбывания наказаний. Значительный перерыв в трудовой деятельности и отсутствие профессиональных навыков у этой категории граждан затрудняют их трудоустройство, создают социальную напряженность в регионах и приводят к росту рецидивной преступности. Отсутствие рабочих мест не позволяет осужденным в должной степени возмещать ущерб, причиненный гражданам и государству, оказывать материальную помощь семьям, рассчитываться за полученное пи- тание и вещевое имущество, приобретать дополнительные продукты питания и предметы первой необходимости. Денежные средства, заработанные осужденными в период отбывания наказания, зачастую являются единственным источником их существования после освобождения [8].

Кризисные явления в финансово-экономической сфере отрицательно сказываются на состоянии социальной сферы. Изменения социально-имущественной структуры населения страны в последние годы характеризовались такими тенденциями, как увеличение численности населения, уровень обеспечения которого ниже прожиточного минимума, и рост имущественной дифференциации [9. С. 165]. Низкий уровень жизни населения, высокая степень дифференциации его доходов, а также значительный уровень бедности традиционно рассматриваются в числе причин преступности, в том числе рецидивной. По результатам проведенного нами опроса сотрудников уголовно-исполнительной системы большинство $(71,6 \%)$ среди общих причин рецидивной преступности назвали такой фактор, как низкий уровень жизни основной части населения, значительное расслоение населения по имущественному признаку ${ }^{1}$.

По официальным данным, численность населения России с доходами ниже прожиточного минимума в 2018 г. составляла 19 млн человек; уровень бедности (отношение количества человек с доходами ниже прожиточного минимума к общей численности населения) - 13,3\% [10]. Однако, по экспертным оценкам, реальные показатели уровня бедности в стране значительно выше официальных. По данным экспертов, около 50\% населения России живет за чертой бедности (70-75 млн человек) [11. С. 320]. Доходы большинства населения ниже официальной среднемесячной зарплаты; в связи с инфляцией и увеличением обязательных выплат реальные доходы граждан в последние годы сократились еще заметнее.

Неудовлетворенность уровнем жизни является серьезным криминогенным фактором. Отсутствие у людей законных способов обеспечения потребностей приводит к поиску способов их удовлетворения незаконным путем, в том числе путем совершения преступлений. Верность данного утверждения подтверждается уголовной статистикой - среди лиц, совершивших преступления, свыше 65\% не имеют постоянного источника доходов [1].

Основная деформация социальной сферы российского общества состоит в резком имущественном расслоении населения. Мировая практика показывает, что предельно критическим значением является соотношение доходов 10\% самых богатых и $10 \%$ самых бедных групп населения как 10:1. Превышение этого соотношения приводит к дестабилизации общества, усилению социального напряжения и агрессии. В России в среднем, по официальным данным, 10\% наиболее обеспеченных граждан в 16,8 раза богаче $10 \%$ самых бедных. В реальности этот показатель выше, так как официальные данные не учитывают скрытые доходы, незаконную прибыль и коррупционные факторы. Так, по расчетам Института социальноэкономических проблем народонаселения Российской 
академии наук, это соотношение составляет 30:1; по данным Московского отделения Росстата в Москве в 2014 г. - 50:1 [11. С. 321]. Кроме того, в России сложилась недопустимая разница в уровне социальноэкономического развития регионов: разрыв между наиболее и наименее экономически обеспеченными регионами страны по показателю подушевого регионального продукта составляет 60-кратную величину, по уровню безработицы -50-кратную.

В трудном материальном положении оказываются лица, освободившиеся из мест лишения свободы. Как отмечалось выше, во время отбывания наказания у многих осужденных отсутствует возможность заработать денежные средства на первое время жизни после освобождения. При этом значительная часть осужденных утрачивает социально значимые контакты и связи. Из мест лишения свободы ежегодно освобождается около 220 тыс. человек [12] По данным сотрудников уголовно-исполнительной системы, около трети осужденных, отбывающих наказания в исправительных учреждениях, не имеют регистрации и постоянного места жительства; практически каждый второй после освобождения сталкивается с проблемами трудоустройства.

Низкая конкурентноспособность на рынке труда бывших осужденных обусловлена отсутствием у многих из них соответствующих профессиональных навыков и мотивации, а также нежеланием работодателей принимать на работу лиц с судимостью по причине их низкой трудовой дисциплины и нередко наличия алкогольной (наркотической) зависимости. Таким образом, освобожденные фактически остаются без средств к существованию; их бытовая и трудовая неустроенность способствует повторному совершению преступлений. В такой ситуации необходимым условием профилактики рецидива должны быть меры содействия со стороны государства и общественных формирований бывшим осужденным в социальнобытовом устройстве.

Однако на сегодняшний день в стране отсутствует единая скоординированная система оказания такой помощи освобожденным из мест лишения свободы. Во-первых, на федеральном уровне не сформирована необходимая законодательная база, регламентирующая различные аспекты государственной поддержки отбывших наказание, вовторых, не созданы специальные службы, целенаправленно и комплексно занимающиеся трудовым и бытовым устройством таких лиц. Федеральный закон от 26.06.2016 г. № 182-Ф3 «Об основах системы профилактики правонарушений в Российской Федерации» в самом общем виде закрепляет ресоциализацию в числе форм профилактического воздействия, определяя ее как комплекс мер социально-экономического, педагогического, правового характера, осуществляемых в целях реинтеграции в общество лиц, отбывших уголовное наказание в виде лишения свободы и (или) подвергшихся иным мерам уголовно-правового характера. При этом конкретных органов и учреждений, участвующих в системе социальной реабилитации, а также их полномочия не называет.
Уголовно-исполнительным законодательством предусмотрено содействие в трудовом и бытовом устройстве освобождаемых осужденных, обеспечение их одеждой, продуктами питания; Уголовноисполнительный кодекс РФ (ст. 180, 181) также предусматривает оплату осужденным проезда к месту жительства, выдачу единовременного пособия при освобождении из исправительного учреждения. Федеральный закон от 10.06.2008 г. № 76-Ф3 «Об общественном контроле за обеспечением прав человека в местах принудительного содержания и о содействия лицам, находящимся в местах принудительного содержания» регламентирует содействие при решении вопросов трудового, жилищно-бытового устройства лиц, отбывающих наказание в местах лишения свободы, а также в решении вопросов, связанных с оказанием им медицинской помощи и предоставлением иных гарантий со стороны общественных объединений. То есть уголовно-исполнительное законодательство определяет меры помощи осужденным в процессе отбывания наказания, а также в рамках их подготовки к освобождению. Правовое регулирование мер государственной поддержки лиц после освобождения от наказания выходят за рамки уголовно-исполнительного права.

Вопросы ресоциализации бывших осужденных в некоторой степени урегулированы региональным законодательством. Так, в ряде субъектов РФ (Республика Башкортостан, Архангельская, Кировская, Тюменская, Ульяновская область, Еврейская автономная область и др.) приняты специализированные законы о социальной адаптации бывших осужденных. В отдельных регионах (Республика Карелия, Саха (Якутия), Татарстан, Камчатский, Краснодарский край и др.) предусмотрено квотирование рабочих мест, а также иные меры экономического стимулирования работодателей, трудоустраивающих граждан, освободившихся из мест лишения свободы. Мероприятия по оказанию поддержки лиц, отбывших наказания, включены в региональные программы социальной поддержки и содействия занятости населения, а также программы профилактики правонарушений. Вместе с тем, как показывают исследования, реализация мероприятий в большинстве регионов фактически заморожена, в связи с отсутствием финансирования. Кроме того, имеет место формальный подход к выполнению задач: большинство мероприятий не предполагают реального оказания помощи освобожденным, о чем свидетельствуют их оценочные формулировки (например, «создание условий», «оказание содействия») [13. С. 38].

Указанные недостатки и пробелы свидетельствуют о деформациях в политико-правовой сфере, детерминирующих рецидивную преступность. Игнорирование государством вопросов трудового и бытового устройства бывших осужденных оборачивается совершением новых преступлений. К числу детерминант рецидивной преступности в данной области следует отнести негативные последствия гуманизации уголовного законодательства, которые привели к необоснованному смягчению уголовной ответственности за рецидив преступлений. Внесенные Федеральным законом от 08.12.2003 г. № 162-Ф3 изменения значительно сузи- 
ли рамки рецидива, ввели ограничения при признании рецидива опасным и особо опасным, установили одинаковый нижний предел наказания при любом виде рецидива в виде одной трети от максимального срока наиболее строгого наказания. После введения таких изменений удельный вес лиц, признанных совершившими преступления при опасном и особо опасном рецидиве, сократился в 2,5 раза (в 2005 г. по сравнению с 2003 г.). Устойчивая тенденция снижения доли опасного и особо опасного рецидива в структуре преступности лиц, имеющих неснятую или непогашенную судимость, имела места до 2008 г. Однако с 2009 г. наблюдается устойчивый рост доли лиц, совершивших преступления при опасном или особо опасном рецидиве. Таким образом, попытки законодателя сократить рецидивную преступность путем искусственного сужения его границ не привели к желаемому результату [14. С. 126]. Более того, как отмечалось выше, доля рецидивных преступлений в структуре российской преступности выросла в два раза. Таким образом, изменения уголовного законодательства не только не дали положительного результата, но и отрицательно сказались на динамике рецидивной преступности.

Гуманизация уголовного законодательства также проявилась в расширении видов освобождения от уголовной ответственности, смягчении его оснований, вследствие чего значительная масса (примерно 20\%) выявленных лиц, совершивших преступления, освобождается от уголовной ответственности. Однако, по данным статистики, в последние годы наблюдается учащение фактов повторного совершения преступлений после освобождения от уголовной ответственности за ранее совершенное преступление. Так, среди лиц, повторно совершающих преступления, 48,4\% тех, кто за предыдущее преступление был освобожден от уголовной ответственности. В связи с этим уместно упомянуть о безнаказанности как серьезном криминогенном факторе. Неадекватное реагирование на преступное деяние лиц, неоднократно совершающих преступления, формирует у них чувство безнаказанности и препятствует полному восстановлению социальной справедливости.
Развитию рецидивной преступности способствуют деформации в духовно-нравственной сфере, обусловленные сложившимся в российском обществе кризисом духовно-нравственных ценностей. Существовавшая длительное время в стране система ценностей и ориентаций была отвергнута, а новая система окончательно не сформировалась, вследствие чего образовались пробелы морального регулирования, получила распространение моральная безнравственность.

Низкий уровень жизни в стране, значительная имущественная дифференциация предопределила преобладание у большинства населения примитивных потребностей, мотивов выживания и борьбы за элементарный уровень существования. В сознании большинства членов общества доминируют не духовные, а материальные ценности. Государство практически самоустранилось от задачи формирования духовной культуры, воспитания нравственности, должного правосознания. Резко ослабла государственная поддержка и финансирование системы образования, науки и культуры [15. С. 254].

К криминогенно значимым деформациям в духовно-нравственной сфере относятся деформации правосознания, которые выражаются в правовой неграмотности, в неправильном отношении к праву и к исполнению правовых предписаний. Низкий уровень правосознания способствует повторному совершению преступлений, так как проявляется в пренебрежительном отношении лиц к уголовно-правовым запретам, неуважении к закону, утрате страха перед наказанием. Следование и пропаганда рецидивистами норм преступной субкультуры способствует криминализации общества. Преступный мир насаждает нравы и обычаи, традиции и нормы, базирующиеся на ценностях криминальной субкультуры, не только допускающие, но и оправдывающие, поощряющие, открыто провоцирующие нарушения уголовноправовых запретов [9. С. 433].

Таким образом, указанные проблемы, сложившиеся в экономической, социальной, политической и духовно-нравственной сфере, на макросоциальном уровне стимулируют развитие рецидивной преступности и выступают ее общесоциальными детерминантами.

\section{ПРИМЕЧАНИЕ}

\footnotetext{
${ }^{1}$ Приведены результаты опроса сотрудников уголовно-исполнительных инспекций и исправительных колоний Управления Федеральной службы исполнений наказаний России по Республике Бурятия в рамках исследования причин и условий рецидивной преступности. Опрос проводился в течение августа 2019 г. по специально разработанной анкете, состоявшей из 20 вопросов, сформулированных в открытой форме. Всего в опросе участвовало 134 сотрудника.
}

\section{ЛИТЕРАТУРА}

1. Состояние преступности. URL: https://xn--b1aew.xn--p1ai/Deljatelnost/statistics

2. Артемьев Н.С., Симонов Р.В. Причины и условия рецидивной преступности и основные меры ее предупреждения // Уголовноисполнительное право. 2006. № 2. С. 6-9.

3. Криминология / под общ. ред. А.И. Долговой. 3-е изд., перераб. и доп. М. : Юр. норма ; НИЦ ИНФРА-М., 2007.912 с.

4. Криминология : учеб. пособие. Стандарт третьего поколения / под ред. В.Н. Бурлакова, Н.М. Кропачева. СПб. : Питер, 2013. 304 с.

5. Шестаков Д.А. Возвращение к криминологической теории причинности // Криминология: вчера, сегодня, завтра. 2015. № 2 (37). С. 88-97.

6. Прозументов Л.М., Шеслер А.В. Криминология (Общая часть) : учеб. пособие. Томск : Издательский Дом Томского государственного университета, 2017. 284 с

7. Михайлов В.В. Кризисные явления в экономике России и пути их преодоления // Управленческое консультирование. 2017. № 4. С. 129-144.

8. Федеральная целевая программа «Развитие уголовно-исполнительной системы (2018-2026 гг.)», утв. Постановлением Правительства РФ от 06.04.2018 № 420 // СЗ РФ. 2018. № 16 (ч. II). Ст. 2374. 
9. Причины преступности в России / Ю.М. Антонян, Е.М. Тимошина [и др.]. М. : ФГКУ «ВНИИ МВД России» ; СПб. : Нестор-История, 2013. $348 \mathrm{c}$.

10. Без просвета: бедных в России стало больше. URL: https://www.gazeta.ru/business/2018/12/10/12090253.shtml (дата обращения: 12.11.2019).

11. Купрещенко Н.П., Федотова Е.А. Дифференциация доходов и бедность населения как угроза экономической безопасности России // Вестник экономической безопасности. 2016. № 3. С. 320.

12. Статистические данные Федеральной службы исполнения наказаний. URL: http://fsin.su/statistics/

13. Климанова О.В. Ресоциализация лиц, отбывших уголовное наказание и освобожденных от него, в нормативных актах: проблемы и противоречия // Юридический вестник Самарского университета. 2018. Т. 4, № 2. С. 34-40.

14. Огурлиева А.А. Современные проблемы рецидива преступлений: причины неэффективности борьбы с рецидивной преступностью // Юридический вестник ДГУ. 2015. Т. 14, № 2. С. 124-127.

15. Номоконов В.А. Причины преступности в современной России: проблема обостряется // Всероссийский криминологический журнал. 2017. T. 11, № 2. C. 247-257.

Статья представлена научной редакцией «Право» 13 февраля 2020 г.

\section{Society-Wide Determinants of Recidivism}

Vestnik Tomskogo gosudarstvennogo universiteta - Tomsk State University Journal, 2020, 457, 261-265.

DOI: $10.17223 / 15617793 / 457 / 31$

Olga V. Filippova, East Siberia State University of Technology and Management (Ulan-Ude, Russian Federation). E-mail: ovalfilippova@yandex.ru

Keywords: recidivism; crime; society-wide determinants; causes of crime; criminogenic factors.

This article discusses the society-wide determinants of recidivism, which has increased significantly in recent years, in Russia. In modern studies, the determinants of recidivism are reduced mainly to the characteristics of offenders and the negative impact of microenvironments on them. Society-wide determinants are insufficiently analyzed. Researchers use various approaches to explain the causes of recidivism. They distinguish objective and subjective factors, primary and secondary, general and specific. When studying the determinants of recidivism it seems expedient to apply a tiered approach. According to this approach, the causes and conditions of crime are considered at three levels: society-wide, sociopsychological, and individual. At the society-wide level, the determinants of crime are contradictions of social being and public consciousness - phenomena at the level of society as a whole. At the sociopsychological level, the causes and conditions of recidivism are the criminogenic effect of recidivists' microenvironment and the low efficiency of preventive work. At the individual level, the causes of recidivism lie in recidivists' antisocial features and in the criminogenic situation, which lead to another offence. In the course of the study, the author examined statistics on recidivism, identified its negative trends, summarized criminological views on the determination of recidivism, analyzed information on the state of the economy, politics, social and spiritual-moral spheres, made conclusions about the impact of negative phenomena on the recurrence of crimes; identified gaps in the current criminal law leading to re-commissions of crimes; conducted a survey of employees of the penitentiary system. As a result of the study, the author came to the following conclusions. Society-wide determinants of recidivism are: aggravation of socioeconomic problems against the backdrop of the global financial crisis, a decrease in the pace and volume of production resulting in the lack of jobs and thus of a permanent source of income for persons with a criminal record; disinterest of business entities in employing such persons as they possess no professional skills and have a low motivation to work; poor organization of assistance in the social adaptation of former convicts; deficiencies in the criminal policy in relation to persons who have previously committed crimes; deformation of legal consciousness and prevalence of criminal subculture standards in society.

\section{REFERENCES}

1. Ministry of Internal Affairs of the Russian Federation (n.d.) Sostoyanie prestupnosti [The state of criminality]. [Online] Available from: https://xn-b1aew.xn--p1ai/Deljatelnost/statistics.

2. Artem'ev, N.S. \& Simonov, R.V. (2006) Reasons and conditions of re-offending and main measures for its prevenuion. Ugolovno-ispolnitel'noe pravo. 2. pp. 6-9. (In Russian).

3. Dolgova, A.I. (ed.) (2007) Kriminologiya [Criminology]. 3d ed. Moscow: Yur. norma; NITs INFRA-M.

4. Burlakov, V.N. \& Kropachev, N.M. (eds) (2013) Kriminologiya [Criminology]. Saint Petersburg: Piter.

5. Shestakov, D.A. (2015) Return to the criminological theory of causality. Kriminologiya: vchera, segodnya, zavtra-Criminology: Yesterday, Today, Tomorrow. 2 (37). pp. 88-97. (In Russian).

6. Prozumentov, L.M. \& Shesler, A.V. (2017) Kriminologiya. Obshchaya chast' [Criminology. General part]. Tomsk: Tomsk State University.

7. Mikhaylov, V.V. (2017) The crisis phenomena in economy of Russia and the way of their overcoming. Upravlencheskoe konsul'tirovanie-Administrative Consulting. 4. pp. 129-144. (In Russian).

8. Russian Federation (2018) Federal'naya tselevaya programma "Razvitie ugolovno-ispolnitel'noy sistemy (2018-2026 gg.)", utv. Postanovleniem Pravitel'stva RF ot 06.04.2018 № 420 [Federal target program "Development of the penal system (2018-2026)", approved by the Decree of the Government of the Russian Federation of 06.04.2018 No. 420]. Corpus of legislative acts of the Russian Federation. 16 (2). Article 2374.

9. Antonyan, Yu.M. et al. (2013) Prichiny prestupnostiv Rossii [Causes of Crime in Russia]. Moscow: FGKU "VNII MVD Rossii"; Saint Petersburg: Nestor-Istoriya.

10. Gazeta.ru. (2018) Bez prosveta: bednykh v Rossii stalo bol'she [No Hope: The number of the poor in Russia have grown]. [Online] Available from: https://www.gazeta.ru/business/2018/12/10/12090253.shtml. (Accessed: 12.11.2019).

11. Kupreshchenko, N.P. \& Fedotova, E.A. (2016) Differentiation of income and poverty as a threat to economic security of Russia. Vestnik ekonomicheskoy bezopasnosti. 3. pp. 318-322. (In Russian).

12. Federal Penitentiary Service of Russia. (2019) Statisticheskie dannye [Statistical Data]. [Online] Available from: http://fsin.su/statistics/.

13. Klimanova, O.V. (2018) Resocialization of persons who have served criminal penalty and were released from it in regulatory acts: legal gaps and contradictions. Yuridicheskiy vestnik Samarskogo universiteta - Juridical Journal of Samara University. 2 (4). pp. 34-40. (In Russian). DOI: 10.18287/2542-047X-2018-4-2-34-40

14. Ogurlieva, A.A. (2015) Modern problems of recidivism: the reasons for the ineffectiveness of the fight against recidivism. Yuridicheskiy vestnik DGU - Law Herald of Dagestan State University. 2 (14). pp. 124-127. (In Russian).

15. Nomokonov, V.A. (2017) Causes of crime in contemporary Russia: the problem is getting worse. Vserossiyskiy kriminologicheskiy zhurnal Russian Journal of Criminology. 2 (11). pp. 247-257. (In Russian). 